\title{
Explaining use of food parenting practices: the importance of predisposing factors and parental cognitions
}

\author{
Dorus WM Gevers ${ }^{1, *}$, Patricia van Assema ${ }^{1}$, Nanne K de Vries ${ }^{1,2}$ and Stef PJ Kremers ${ }^{1}$ \\ 'Department of Health Promotion, NUTRIM School for Nutrition and Translational Research in Metabolism, \\ Maastricht University Medical Centre, PO Box 616, Maastricht 6200, The Netherlands: ${ }^{2}$ Department of Health \\ Promotion, CAPHRI School for Public Health and Primary Care, Maastricht University Medical Centre, Maastricht, \\ The Netherlands
}

Submitted 29 0ctober 2016: Final revision received 3 May 2017: Accepted 4 May 2017: First published online 13 July 2017

\begin{abstract}
Objective: The high energy intake from energy-dense foods among children in developed countries is undesirable. Improving food parenting practices has the potential to lower snack intakes among children. To inform the development of interventions, we aimed to predict food parenting practice patterns around snacking (i.e. 'high covert control and rewarding', 'low covert control and non-rewarding', 'high involvement and supportive' and 'low involvement and indulgent').

Design: A cross-sectional survey was conducted. To predict the patterns of food parenting practices, multinomial logistic regression analyses were run with 888 parents. Predictors included predisposing factors (i.e. parents' and children's demographics and BMI, parents' personality, general parenting, and parenting practices used by their own parents) and parents' cognitions (i.e. perceived behaviour of other parents, subjective norms, attitudes, self-efficacy and outcome expectations).

Setting: The Netherlands (October-November 2014).

Subjects: Dutch parents of children aged 4-12 years old.

Results: After backward elimination, nineteen factors had a statistically significant contribution to the model (Nagelkerke $R^{2}=0 \cdot 63$ ). Overall, self-efficacy and outcome expectations were among the strongest explanatory factors. Considering the predisposing factors only, the general parenting factor nurturance most strongly predicted the food parenting clusters. Nurturance particularly distinguished highly involved parents from parents employing a pattern of low involvement.

Conclusions: Parental cognitions and nurturance are important factors to explain the use of food parenting practices around snacking. The results suggest that intervention developers should attempt to increase self-efficacy and educate parents about what constitute effective and ineffective parenting practices. Promoting nurturance might be a prerequisite to achieve prolonged change.
\end{abstract}

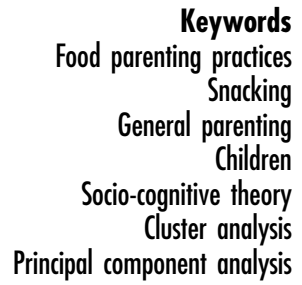

The high energy intake from energy-dense foods among children in developed countries ${ }^{(1-3)}$ is undesirable as such foods tend to be of little nutritional value and are superfluous to a healthy $\operatorname{diet}^{(4)}$. Several studies suggest that snacking has increased during the last few decades, thereby contributing to excessive energy intakes ${ }^{(5-8)}$. It is important to invert this trend and establish healthy dietary patterns in childhood since children's dietary behaviours ${ }^{(9)}$ and overweight ${ }^{(10)}$ track into adulthood. Parents can have a significant impact on their children's food consumption through their food-specific parenting practices $^{(11)}$ (i.e. behaviours used to shape a child's diet, such as restricting children's access to snack foods or modelling healthy food intake $\left.{ }^{(12)}\right)$. In an earlier publication, based on a cluster analytic approach, we demonstrated that four categories of Dutch parents could be distinguished when it comes to food parenting practices (FPP) around snacking $^{(13)}$ (see Table 1). Children whose parents employed the 'high involvement and supportive' pattern had lower energy-dense snack food intakes compared with children whose parents employed any of the other three patterns (i.e. 'low involvement and indulgent', 'high covert control and rewarding' and 'low covert control and non-rewarding'). Involved and supportive parents are healthy role models, create a supportive home food environment and set clear boundaries regarding snacking. 
Table 1 Four patterns of food parenting practices around snacking (outcome variable)

\begin{tabular}{lc}
\hline Pattern & $\begin{array}{c}\text { Food parenting practices that particularly } \\
\text { characterize the pattern }\end{array}$ \\
\hline $\begin{array}{c}\text { 'High covert control and } \\
\text { rewarding' }\end{array}$ & $\begin{array}{c}\text { Low availability and accessibility of snack } \\
\text { foods, avoidance of unhealthy } \\
\text { modelling, high use of instrumental } \\
\text { and emotional feeding }\end{array}$ \\
'Low covert control and \\
non-rewarding'
\end{tabular} $\begin{gathered}\text { High availability and accessibility of } \\
\text { snack foods, low avoidance of } \\
\text { unhealthy modelling, low use of } \\
\text { instrumental and emotional feeding } \\
\text { 'High involvement and } \\
\text { supportive' } \\
\begin{array}{c}\text { High use of responsive parenting } \\
\text { practices such as encouragement and } \\
\text { involving, being a healthy role model, } \\
\text { providing a healthy food environment, } \\
\text { setting rules, low use of instrumental } \\
\text { and emotional feeding } \\
\text { Low use of responsive parenting } \\
\text { practices such as encouragement and } \\
\text { involving, not being a healthy role } \\
\text { model, having an unhealthy food } \\
\text { environment, permissive, low use of } \\
\text { instrumental and emotional feeding }\end{array} \\
\text { 'Low involvement and } \\
\text { indulgent' }\end{gathered}$

Parents exerting covert control try to limit unhealthy food intakes in ways that are not visible for their children, such as by confining the availability of unhealthy foods in their homes. Instrumental and emotional feeding (referred to as 'rewarding' in Table 1) imply that children receive food in exchange for good behaviour or to regulate their emotions.

Intervention developers aiming to promote the use of desirable FPP should know their determinants and, subsequently, fit theoretical methods and practical applications in order to evoke maximal behavioural change ${ }^{(14)}$. Therefore, research on the precursors of parenting practices is essential. So far, research has mainly linked demographic factors to FPP. Another potential precursor includes the general parenting style of parents: evidence shows that parenting practices, although they are domain specific (e.g. food or physical activity), find their origin in general parenting ${ }^{(15)}$. Personality serves as a guiding principle of a person's behaviour ${ }^{(16,17)}$. Consequently, personality might be reflected in general parenting ${ }^{(18)}$ and also relate to parenting practices. Probably, the use of parenting practices also traces back to childhood experiences and is linked with practices used by one's own parents (i.e. the practices imposed during the parent's own childhood). This hypothesis is supported by qualitative research ${ }^{(19)}$ and parallels Belsky's theory on determinants of general parenting ${ }^{(18)}$. Besides the more distal factors such as general parenting and personality, other potential, more proximal, precursors of parenting practices include the ones specified by socio-cognitive theories of health behaviour. For instance, the Social Cognitive Theory ${ }^{(20)}$ stresses the importance of outcome expectations as well as modelling in shaping behaviour. Parents might favour certain practices by considering their expected effectiveness (i.e. outcome expectations) or by considering practices used by other parents (i.e. vicarious learning or modelling). Self-efficacy is another core concept of the Social Cognitive Theory and should be considered here as well, in view of evidence indicating that parents of obese children had less confidence in managing children's energy balance-related behaviours ${ }^{(21)}$. In addition to modelling, another form of social influence, subjective norm ${ }^{(22)}$, might be important too. This reflects the degree to which parents find that most people, who are important to them, think they should employ particular parenting practices. Finally, parents' attitude towards the child snacking more in general is expected to determine the type of practices used. Two sets of determinants formed our research framework: predisposing factors (e.g. general parenting, personality) and parental cognitions (e.g. self-efficacy, subjective norms; see Fig. 1). The present paper reports on the relative importance of both sets of determinants in explaining a parent's pattern of FPP and describes the contribution of each single factor to this exploratory model.

\section{Methods}

\section{Study design, setting and participants}

The full study design has been described elsewhere ${ }^{(13)}$. In sum, 1985 Dutch parents of 4- to 12-year-old children were recruited nationwide by a research agency (i.e. Flycatcher Internet Research) and invited to fill out an online questionnaire. Participants received credit points for participation that could be exchanged for gifts: completion of the current study yielded approximately 5.56 Euros. Considering the 'Dutch Medical Research Involving Human Subjects Act ${ }^{\text {'(23), }}$ the study was exempt from ethical review.

\section{Outcome variable}

The outcome variable was the type of FPP pattern. These patterns were derived from a two-step cluster analysis (i.e. hierarchical cluster analysis followed by a non-hierarchical cluster analysis) on twenty-one FPP around snacking ${ }^{(13)}$, including the following constructs: encouragement, rewarding, discussing, providing feedback, involving, educating, healthy modelling, unhealthy modelling avoidance, availability of healthy foods, accessibility of healthy foods, visibility of healthy foods, limited availability of unhealthy foods, limited accessibility of unhealthy foods, structure, meal routines, permissiveness, rules, monitoring, instrumental feeding, emotional feeding and pressure to eat. Four distinct patterns were derived (see Table 1), which were stable according to a cross-validation procedure (i.e. Cohen's $\kappa$ of $0 \cdot 97)$ and characterized as indicated in Table $1^{(13)}$.

\section{Measures}

Predisposing factors

Background variables. Respondents were asked to report their own age, gender, work status, postal code 


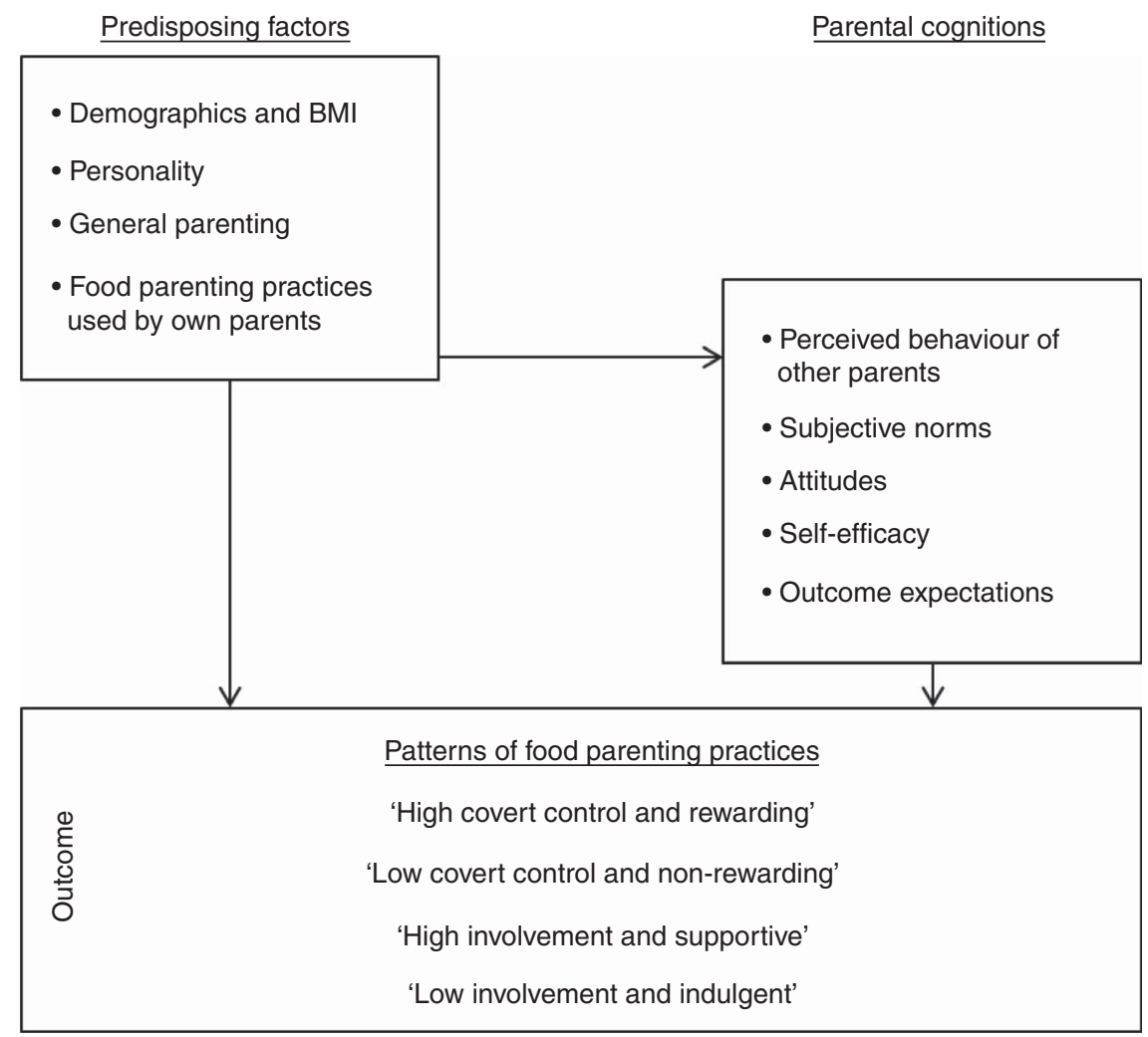

Fig. 1 Research framework to examine the relative importance of predisposing factors and parental cognitions in explaining food parenting practices

(to calculate a factor score for their socio-economic position (SEP); $-4=$ low; $4=$ high $^{(24)}$ ), body height and weight (to calculate parental BMI), and their child's age, gender, and body height and weight (to calculate the child's BMI $Z$-score using a reference population ${ }^{(25)}$ ). The respondents' educational level and ethnicity were known to the research agency.

Parent's personality. For measuring the personality dimensions of extraversion, conscientiousness, agreeableness, emotional stability and openness to experience, the Dutch thirty-item 'Quick Big Five' (QBF) questionnaire ${ }^{(26)}$ was used. Parents were asked to rate personality traits on a 7-point Likert scale. Cronbach's $\alpha$ values of the five personality dimensions within the current sample were all above $0 \cdot 84$.

General parenting. General parenting was assessed using thirty-two items from the validated Comprehensive Parenting General Parenting Questionnaire (CGPQ) ${ }^{(27)}$ on a 5-point Likert scale, ranging from 1 ( = 'strongly disagree') to 5 ( = 'strongly agree'). Five general parenting constructs were measured, including nurturance, structure, behavioural control, coercive control and overprotection. Each of these five general parenting constructs consisted of two to four sub-constructs, of which 'physical punishment' (a sub-construct of coercive control) was not included in the current study. One item within structure (i.e. 'I teach my child to keep his/her bedroom clean and orderly') and two items within behavioural control (i.e. 'I make sure I give my child lots of freedom to make mistakes and learn from them' and 'I give my child a lot of freedom to make up his/her own mind') were dropped because of low corrected item-total correlations. The Cronbach's $\alpha$ values of the five general parenting factors ranged from 0.59 to 0.76 .

Food parenting practices used by own parents. As an indicator of 'practices used by own parents during childhood', participants were asked to indicate to what extent their own parents used to employ the twenty-one FPP that were used to cluster parents into the four groups. The items were formulated as follows: "My own parents (caregivers) used to ... when I was a child' and had to be answered on a 5-point Likert scale ranging from 1 (= 'strongly disagree') to 5 ( = 'strongly agree'), with the possibility to answer 'I don't know'. Exploratory factor analyses (i.e. principal component analysis (PCA)) using oblique rotation were performed to derive factors and create scales using mean scores from the items because they were expected to be multidimensional. 'I don't know' answers were recoded to the middle value $(=3)$. Eigenvalue $>1.0$ was used as a criterion to retain factors. Items were dropped for PCA if factor loadings were $<0.40$ or showed cross-loadings. PCA resulted in five factors referring to parenting practices used by own parents, with moderate to good Cronbach's $\alpha$ except for one (i.e. the scale 'pressure to eat and rewarding'). Example items, reliability statistics and factor loadings of the scales used to predict parenting practices are presented in Table 2. 
Table 2 Scales used to predict food parenting practices

\begin{tabular}{|c|c|c|c|c|c|}
\hline Factor & Example item & Final no. of items & $\begin{array}{c}\text { CITC } \\
\text { (range) }\end{array}$ & $\begin{array}{l}\text { Factor loadings } \\
\quad \text { (range) }\end{array}$ & $\begin{array}{c}\text { Cronbach's } \\
a\end{array}$ \\
\hline \multicolumn{6}{|l|}{ Predisposing factors } \\
\hline Personality† (QBF) ${ }^{(25)}$ & 'Please indicate to what degree the following traits apply to you' & & & & \\
\hline Extraversion & Talkative & 6 & $0.66-0.78$ & NA & 0.90 \\
\hline Conscientiousness & Neat & 6 & $0.62-0.83$ & NA & 0.90 \\
\hline Agreeableness & Helpful & 6 & $0.60-0.74$ & NA & 0.88 \\
\hline Emotional stability & Nervous & 6 & $0.45-0.74$ & NA & 0.84 \\
\hline Openness to experience & Creative & 6 & $0.51-0.71$ & NA & 0.84 \\
\hline General parenting $\ddagger(C G P Q)^{(26)}$ & 'How much do you agree or disagree with the following statements?' & & & & \\
\hline Nurturance & 'I know exactly when my child has difficulty with something' & 8 & $0.41-0.56$ & NA & 0.76 \\
\hline Structure & 'When I tell my child I will do something, I do it' & 7 & $0.27-0.44$ & NA & 0.59 \\
\hline Behavioural control & 'I make sure that my child understands what I expect of him/her' & 6 & $0.28-0.46$ & NA & 0.65 \\
\hline Coercive control & 'I make my child feel guilty when he/she does not meet my expectations' & 4 & $0.29-0.41$ & NA & 0.58 \\
\hline Overprotection & 'Every free minute I have I spend with my child' & 4 & $0.35-0.50$ & NA & 0.65 \\
\hline FPP used by own parentsł & 'My own parents (caregivers) used to $\ldots$ when I was a child' & & & & \\
\hline Covert unhealthy food control & '... limit the availability of EDSF in the house for me' & 4 & NA & -0.42 to -0.79 & 0.59 \\
\hline Healthy food availability, rules, encouragement & ' $\ldots$ make sure healthy foods were available at home for me' & 7 & NA & $0.47-0.89$ & 0.87 \\
\hline Instrumental and emotional feeding & '... give me EDSF to reward me for good behaviour' & 2 & NA & $0.82-0.87$ & 0.66 \\
\hline Meal practices & '... involve me in food-related activities' & 4 & NA & $0.45-0.84$ & 0.72 \\
\hline Pressure to eat and rewarding & ' $\ldots$ insist that I eat or finished a food item' & 2 & NA & $-0.53-0.63$ & NAT \\
\hline \multirow{2}{*}{\multicolumn{6}{|c|}{$\begin{array}{l}\text { Parental cognitions } \\
\text { Perceived behaviour of other parents } \ddagger\end{array}$}} \\
\hline & & & & & \\
\hline Covert unhealthy food control & '... consciously refrain from eating EDSF when their child is around' & 4 & NA & $0.53-0.73$ & 0.69 \\
\hline Healthy food availability, rules, encouragement & $\therefore$ make sure healthy foods are visible for their child' & 9 & NA & $0.46-0.85$ & 0.87 \\
\hline Instrumental and emotional feeding & '... give their child EDSF to make him/her feel better' & 3 & NA & $0.65-0.75$ & 0.59 \\
\hline Meal practices & '... involve their child in food-related activities' & 3 & NA & $0.73-0.80$ & $0 \cdot 76$ \\
\hline Subjective normsł & 'Most people, who are important to me, think I should ...' & & & & \\
\hline Covert unhealthy food control & '... consciously refrain from eating EDSF when my child is around' & 4 & NA & -0.56 to -0.74 & 0.79 \\
\hline Healthy food availability, rules, encouragement & '... have rules for my child about eating EDSF' & 10 & NA & $0.40-0.85$ & 0.92 \\
\hline Instrumental and emotional feeding & $\therefore$... give my child EDSF to make him/her feel better' & 3 & NA & $0.73-0.78$ & 0.63 \\
\hline Meal practices & '... teach my child things about food' & 4 & NA & $0.70-0.85$ & 0.82 \\
\hline Attitude $\neq$ & 'If my child eats a lot of EDSF ...' & & & & \\
\hline Benefits of child's EDSF intake & '... he/she will think I am a good father/mother' & 5 & NA & $0.63-0.80$ & 0.80 \\
\hline Negative effects of child's EDSF intake & '... he/she will be less able to concentrate' & 5 & NA & $0.53-0.69$ & 0.63 \\
\hline Self-efficacy $¥, \S$ & 'I think it is difficult to ...' & & & & \\
\hline Covert unhealthy food control and rules & ' $\ldots$ limit the availability of EDSF in the house for my child' & 7 & NA & $0.43-0.78$ & 0.81 \\
\hline Healthy food availability and encouragement & $\therefore$ make sure healthy foods are available at home for my child' & 5 & NA & -0.54 to -0.85 & 0.85 \\
\hline Meal practices & '... ensure healthy mealtime habits' & 4 & NA & $0.57-0.79$ & 0.72 \\
\hline Permissiveness and pressure & $\therefore$ insist that my child eats or finishes a food item' & 3 & NA & $0.45-0.75$ & 0.50 \\
\hline Outcome expectations§, $\|$ & 'If I ..., my child will' & & & & \\
\hline Covert unhealthy food control & '... limit the accessibility of EDSF in the house for my child' & 2 & NA & $0.86-0.90$ & 0.77 \\
\hline Healthy food availability and encouragement & '... make sure healthy foods are accessible at home for my child' & 6 & NA & $0.66-0.85$ & 0.92 \\
\hline Instrumental and emotional feeding & $\therefore$ give my child EDSF to reward me for good behaviour' & 3 & NA & $0.61-0.82$ & 0.66 \\
\hline Meal practices & '... teach my child things about food' & 4 & NA & $0.60-0.81$ & 0.80 \\
\hline Pressure to eat, rules, structure and feedback & '... respond to my child 's eating behaviour by providing him/her with feedback' & 4 & NA & $0.52-0.69$ & 0.58 \\
\hline
\end{tabular}




\section{Parental cognitions}

Perceived behaviour of other parents and subjective norms. Items used to measure social influences (i.e. perceived behaviour of other parents, subjective norms) also referred to the twenty-one individual FPP around snacking and entered a PCA in a similar fashion. 'Perceived behaviour of other parents' was assessed using the question: 'Most parents ...' followed by the twenty-one individual FPP. 'Subjective norms' were assessed using items starting with: 'Most people, who are important to me, think I should ...' All questions were accompanied with a 5-point Likert scale ranging from 1 (= 'strongly disagree') to 5 (='strongly agree') and a possibility to answer 'I don't know'.

Attitude. Qualitative interviews with fifteen parents from the target population informed the development of the attitude items. Two sets of five items were formulated to assess parents' attitude towards benefits (Cronbach's $\alpha=0.80$ ) and negative effects (Cronbach's $\alpha=0.63$ ) of a high snack intake by their child. Attitude items were rated on a 5-point Likert-scale ranging from 'strongly disagree' to 'strongly agree' and loaded on two factors, thereby confirming the attitude dichotomy.

Self-efficacy and outcome expectations. In line with items used to measures social influences (i.e. perceived behaviour of other parents, subjective norms), self-efficacy and outcome expectations items referred to the twentyone FPP and entered the PCA. Self-efficacy items started with the following phrase: 'I think it is difficult to ...' and were also rated on a 5-point Likert scale ranging from 'strongly disagree' to 'strongly agree'. Because self-efficacy tends to be of minor importance with regard to instrumental feeding and emotional feeding, we decided not to measure self-efficacy for both constructs. Outcome expectations were assessed using the statement: 'If I ..., my child will' and a 5-point scale ranging from 1 ( = 'eat far less snack foods') to 5 (= 'eat a lot more snack foods'). Four self-efficacy factors (Cronbach's $\alpha$ ranging from 0.50 to $0 \cdot 81$ ) and five outcome expectation factors (Cronbach's $\alpha$ ranging from 0.58 to 0.71 ) were derived. Self-efficacy and outcome expectations were reverse recoded so that higher scores indicate a higher self-efficacy and positive outcome expectations (i.e. lower child snack food intake), respectively.

\section{Statistical analysis}

To diagnose multicollinearity, correlations between predictor variables were explored and variance inflation factors were calculated through a linear regression analysis with all predictors as independent variables. A cut-off value of $>0.8$ for correlations ${ }^{(28)}$ and $>10$ for variance inflation factors ${ }^{(29)}$ was applied for multicollinearity. To predict the patterns of FPP, multinomial logistic regression analyses were run using the 'high involvement and supportive' pattern as the reference category. Each predictor was tested individually and in a total model by using backward elimination. Subsequently, significant predictors in the final model were entered into two separate multinomial logistic regression analyses (i.e. one including predisposing factors and one including parental cognitions) to investigate the importance of both sets of predictors by assessing Nagelkerke $R^{2}$ values. All analyses were conducted using the statistical software package IBM SPSS Statistics version 20. $P$ values $<0.05$ were considered statistically significant.

\section{Results}

\section{Sample}

The sample consisted of 888 parents with a mean age of 40.6 (sD 5.8) years. Of the sample, $65.2 \%$ were female; $45.3 \%$ had an intermediate and $43.6 \%$ had a high educational level. Most parents were of Dutch ethnicity (91.0\%) and were employed (79.3\%). Their mean BMI was $25 \cdot 2(\mathrm{sD} 4 \cdot 2) \mathrm{kg} / \mathrm{m}^{2}$ and the mean SEP score was $0 \cdot 1$ (SD 1.2). Regarding BMI category, 54.2\% had a healthy weight (i.e. $18 \cdot 5-24.9 \mathrm{~kg} / \mathrm{m}^{2}$ ) and $45.2 \%$ were overweight (i.e. $\geq 25 \cdot 0 \mathrm{~kg} / \mathrm{m}^{2}$ ). The mean age of the children was 7.9 (SD 2.6) years with half of them being female (49.7\%). Their mean BMI $Z$-score was 0.19 (SD 1.4), with $73.2 \%$ being healthy weight and $14.6 \%$ overweight according to Barlow's cut-off points ${ }^{(30)}$.

\section{Predictors of patterns of food parenting practices}

Multicollinearities between the scales were not found. Results from the multinomial logistic regression analysis showed that after backward elimination, nineteen factors had a statistically significant contribution to the final model (Nagelkerke $R^{2}=0 \cdot 63$; Table 3 ).

All parental cognitions remained in the model, except for the factors measuring perceived behaviour of other parents, one out of four factors measuring subjective norms, and two out of five factors measuring outcome expectations. Overall, self-efficacy and outcome expectations were among the strongest predictors: parents were more likely to be highly involved and supportive in food parenting, rather than employ any other pattern, if they had a high self-efficacy and more positive outcome expectations regarding the 'availability of healthy food and encouragement' and more positive outcome expectations regarding 'meal practices'.

Concerning the predisposing factors, in particular nurturance most strongly predicted food parenting clusters. Parents scoring high on nurturance were less likely to have the 'low involvement and indulgent' and the 'high covert control and rewarding' pattern, rather than having the 'high involvement and supportive' pattern. From the background variables, child age and SEP remained significant explanatory factors of cluster membership in the final model: higher-SEP parents were more likely to have the 'low involvement and indulgent' pattern, rather than the opposite one (i.e. 'high involvement and supportive'). 
Table 3 Predictors of food parenting practice patterns around snacking among parents of children aged 4-12 years, the Netherlands (October-November 2014): OR and $P$ values from the univariate and backward multinomial logistic regression analyses

\begin{tabular}{|c|c|c|c|c|c|c|}
\hline \multirow{2}{*}{$\begin{array}{l}\text { Reference category = high involvement } \\
\text { and supportive }\end{array}$} & $\begin{array}{c}\text { High covert } \\
\text { control and } \\
\text { rewarding } \\
\end{array}$ & $\begin{array}{c}\text { Low covert } \\
\text { control and } \\
\text { non-rewarding }\end{array}$ & $\begin{array}{c}\text { Low } \\
\text { involvement } \\
\text { and indulgent } \\
\end{array}$ & $\begin{array}{c}\text { High covert } \\
\text { control and } \\
\text { rewarding }\end{array}$ & $\begin{array}{c}\text { Low covert } \\
\text { control and } \\
\text { non-rewarding }\end{array}$ & $\begin{array}{l}\text { Low } \\
\text { involvement } \\
\text { and indulgent }\end{array}$ \\
\hline & \multicolumn{3}{|c|}{ Univariate ( $n 871$ to 888 ) } & \multicolumn{3}{|c|}{ Backward procedure ( $n$ 864) } \\
\hline Nagelkerke $R^{2}$ & \multicolumn{3}{|c|}{ NA } & \multicolumn{3}{|c|}{0.63} \\
\hline \multirow{2}{*}{\multicolumn{7}{|c|}{$\begin{array}{l}\text { Predisposing factors } \\
\text { Background variables }\end{array}$}} \\
\hline & & \multicolumn{5}{|c|}{ Background variables } \\
\hline Parent age & 0.99 & 1.03 & $1.04^{*}$ & & & \\
\hline Parent gender† & 1.02 & 0.75 & 1.47 & & & \\
\hline Parent BMI & 0.98 & 0.99 & $1.05^{\star}$ & & & \\
\hline Parent ethnicity $\ddagger$ & 1.03 & 1.85 & 0.95 & & & \\
\hline Parent SEP & 1.07 & 0.96 & $1 \cdot 26^{*}$ & 1.01 & 0.97 & $1 \cdot 34^{*}$ \\
\hline Parent educational level low§ & 1.84 & 1.78 & $2 \cdot 33^{*}$ & & & \\
\hline Parent educational level intermediate§ & 1.25 & $1 \cdot 12$ & $1 \cdot 25$ & & & \\
\hline Parent work status $\|$ & 0.81 & 0.97 & 1.37 & & & \\
\hline Child gendert & 0.82 & 0.85 & $0.59^{*}$ & & & \\
\hline Child age & $0.91^{*}$ & $1 \cdot 13^{*}$ & $1 \cdot 13^{*}$ & $0.86^{\star \star *}$ & 1.04 & $1.07^{*}$ \\
\hline Child BMI Z-score & 1.13 & 0.95 & $1.23^{*}$ & & & \\
\hline \multicolumn{7}{|l|}{ Parent's personality } \\
\hline Extraversion & $0.95^{\star \star \star}$ & 0.98 & $0.93^{\star \star \star}$ & & & \\
\hline Conscientiousness & $0.97^{\star}$ & 0.97 & $0.91^{\star \star \star}$ & & & \\
\hline Agreeableness & $0.86^{\star * *}$ & $0.90^{* * *}$ & $0.77^{* \star \star}$ & & & \\
\hline Emotional stability & $0.96^{*}$ & 0.99 & $0.94^{* \star *}$ & & & \\
\hline Openness to experience & $0.94^{* * *}$ & $0.93^{* * *}$ & $0.90^{* \star *}$ & 0.97 & 0.95 & 0.95 \\
\hline \multicolumn{7}{|l|}{ General parenting } \\
\hline Nurturance & $0.17^{\star \star \star}$ & $0.35^{\star \star *}$ & $0.04^{\star \star \star}$ & $0.51^{*}$ & 0.69 & $0.22^{\star \star \star}$ \\
\hline Structure & $0.29^{\star \star \star}$ & 0.95 & $0.12^{\star * *}$ & & & \\
\hline Behavioural control & $0.61^{\star}$ & $0.57^{\star \star}$ & $0.20^{\star \star \star}$ & & & \\
\hline Overprotection & 1.04 & $0.74^{*}$ & $0.70^{\star}$ & & & \\
\hline Coercive control & $1 \cdot 50^{\star \star}$ & 0.87 & $1.53^{\star *}$ & & & \\
\hline \multicolumn{7}{|l|}{ FPP used by own parents } \\
\hline Covert unhealthy food control & 0.93 & $0.34^{\star * *}$ & $0.51^{\star \star \star}$ & 1.37 & $0.54^{\star \star \star}$ & 0.73 \\
\hline Healthy food availability, rules, encouragement & $0.47^{\star \star \star}$ & $0.42^{\star \star *}$ & $0.26^{\star \star \star}$ & $0.58^{*}$ & 0.72 & $0.57^{\star}$ \\
\hline Instrumental and emotional feeding & $1.43^{\star * *}$ & $0.58^{* * *}$ & 1.12 & 1.08 & $0.65^{\star *}$ & 0.71 \\
\hline Meal practices & $0.57^{\star \star *}$ & $0.50^{\star \star \star}$ & $0.30^{* \star *}$ & $1 \cdot 20$ & 0.77 & 0.69 \\
\hline \multicolumn{7}{|l|}{ Parental cognitions } \\
\hline \multicolumn{7}{|l|}{ Perceived behaviour of other parents } \\
\hline Covert unhealthy food control & 1.33 & $0.53^{* * *}$ & 0.73 & & & \\
\hline Healthy food availability, rules, encouragement & $0 \cdot 81$ & $0.52^{* * *}$ & $0.38^{* \star *}$ & & & \\
\hline Instrumental and emotional feeding & $1 \cdot 17$ & $0.64^{\star *}$ & 0.75 & & & \\
\hline Meal practices & 0.78 & $0.66^{*}$ & $0.43^{\star \star \star}$ & & & \\
\hline \multicolumn{7}{|l|}{ Subjective norms } \\
\hline Covert unhealthy food control & 0.96 & $0.33^{\star * *}$ & $0.54^{\star \star \star}$ & & & \\
\hline Healthy food availability, rules, encouragement & $0.58^{\star \star *}$ & $0.33^{* * *}$ & $0.32^{\star \star \star}$ & & & \\
\hline Instrumental and emotional feeding & $1.52^{\star \star}$ & $0.43^{\star \star \star}$ & $1 \cdot 10$ & 0.81 & $0.45^{\star * *}$ & 0.76 \\
\hline Meal practices & $0.52^{\star \star \star}$ & $0.36^{\star \star \star}$ & $0.39^{\star \star \star}$ & $0.47^{\star \star \star}$ & $0.67^{*}$ & $0.46^{\star *}$ \\
\hline \multicolumn{7}{|l|}{ Attitude } \\
\hline Benefits of child's EDSF intake & $3 \cdot 23^{\star \star \star}$ & 1.20 & $4.52^{\star \star \star}$ & $1.98^{\star \star \star}$ & $1 \cdot 13^{\star}$ & $2 \cdot 29^{\star \star}$ \\
\hline Negative effects of child's EDSF intake & $0.52^{\star \star \star}$ & $0.37^{\star * \star}$ & $0.20^{\star \star *}$ & 0.94 & 0.75 & $0.34^{\star \star \star}$ \\
\hline \multicolumn{7}{|l|}{ Self-efficacy } \\
\hline Covert unhealthy food control and rules & $0.22^{\star \star *}$ & $0.64^{*}$ & $0.11^{* \star *}$ & 0.65 & 0.88 & $0.29^{\star \star \star}$ \\
\hline Healthy food availability and encouragement & $0 \cdot 15^{\star \star \star}$ & $0.36^{* * *}$ & $0.09^{\star \star \star}$ & $0.23^{* \star *}$ & $0.31^{* * *}$ & $0 \cdot 15^{\star \star \star}$ \\
\hline Meal practices & $0.31^{* * *}$ & $0.67^{*}$ & $0.16^{\star \star \star}$ & $0.61^{*}$ & 0.80 & $0.32^{\star \star \star}$ \\
\hline Permissiveness and pressure & $0.53^{\star \star *}$ & 0.91 & $0.54^{\star \star \star}$ & 1.34 & $1 \cdot 16$ & $2 \cdot 62^{\star \star \star}$ \\
\hline \multicolumn{7}{|l|}{ Outcome expectations } \\
\hline Covert unhealthy food control & $0.73^{*}$ & $0.18^{\star \star \star}$ & $0.40^{* \star *}$ & 0.93 & $0.31^{\star \star \star}$ & 0.69 \\
\hline Healthy food availability and encouragement & $0.35^{\star \star \star}$ & $0.14^{\star \star \star}$ & $0.09^{* \star *}$ & $0.39^{* * *}$ & $0 \cdot 27^{\star \star *}$ & $0 \cdot 14^{\star \star \star}$ \\
\hline Instrumental- and emotional feeding & $1.84^{* * *}$ & 1.28 & $3.40^{* * *}$ & 1.32 & $0.63^{*}$ & 1.68 \\
\hline Meal practices & $0 \cdot 28^{\star \star \star}$ & $0.14^{\star \star \star}$ & $0.07^{* \star *}$ & & & \\
\hline Pressure to eat, rules, structure and feedback & $0.44^{\star \star *}$ & $0.28^{* * *}$ & $0 \cdot 20^{\star \star *}$ & & & \\
\hline
\end{tabular}

SEP, socio-economic position; FPP, food parenting practice; EDSF, energy-dense snack food; NA, not assessed/not applicable.

${ }^{\star} P<0.05 ;{ }^{\star \star} P<0.01 ;{ }^{\star \star \star} P<0.001$.

$\dagger 1$ = 'male'; 2 = 'female'.

$\$ 1$ = 'Dutch'; 2 = 'non-Dutch'.

$\$ 1$ = 'low'; 2 = 'intermediate'; 3 = 'high'.

$\| 1$ = 'employed'; 2 = 'non-employed'. 
Parents of younger children were more likely to covertly control unhealthy foods and reward, rather than being highly involved and supportive, and parents of older children were more likely to have the 'low involvement and indulgent' pattern, rather than being highly involved and supportive. Parents' current use of FPP also appeared to be related to the ones used by their own parents. From those factors, the strongest predictor was the former use of covert unhealthy food control: if their own parents highly used covert unhealthy food control, parents were more likely to be highly involved and supportive, rather than being member of the 'low covert control and non-rewarding' cluster. The two separate models, one including predisposing factors and one including parental cognitions from the final model, yielded Nagelkerke $R^{2}$ values of 0.37 and 0.55 , respectively.

\section{Discussion}

In a previous study, we identified four different categories of Dutch parents with patterns of $\mathrm{FPP}^{(13)}$. The current study aimed to explain membership of these patterns and found that parental cognitions were generally stronger predictors than predisposing factors, which included, among others, personality and general parenting. The greatest effect sizes were found among comparisons between the 'high involvement and supportive' cluster and its opposite, the 'low involvement and indulgent' cluster. Self-efficacy and outcome expectations regarding 'healthy food availability and encouragement' were the two factors that best discriminated highly involved and supportive parents from all three other types of parents. Parents were more likely to be highly involved and supportive if they had a high self-efficacy and more positive outcome expectations regarding making healthy foods available, accessible and visible, and regarding encouraging and modelling healthy food intake. These results contribute to the expanding research focus ${ }^{(31-35)}$ on the role of selfefficacy in parents' energy balance-related parenting practices. Consequently, the increased attention of interventions to address self-efficacy seems to be justified ${ }^{(36,37)}$. In addition, the results demonstrate that parents might decide not to use some parenting practices because they believe they are not effective in lowering children's energy-dense snack food intake. In contrast to subjective norms, perceived behaviour of other parents was not predictive for parents' use of parenting practices, probably because of the moderate-sized intercorrelations between these factors. It has previously been highlighted that parents misperceive other parents' acceptance of children's frequent snacking ${ }^{(38)}$, suggesting that parents' subjective norms regarding the use of parenting practices around snacking might be a misperception of the actual norm too. This hypothesis might be addressed in future research. Only a few studies have used theories of health behaviour to predict the use of FPP. For instance, Theory of Planned Behaviour constructs (i.e. attitudes, social norms, perceived behavioural control and intention) and outcome expectations were significant predictors in one study, which specifically focused on parents' tracking behaviour of snack food intake ${ }^{(39)}$. Another line of research focused on predicting the use of vegetable parenting practices using a model that included, among others, Theory of Planned Behaviour and Self Determination Theory constructs $^{(40)}$. Habits most strongly predicted effective and ineffective parenting practices related to vegetable intake ${ }^{(41,42)}$. Since the target populations and type of FPP were different across these studies and the current research, the results cannot easily be merged to indicate the most important predictors.

Besides parental cognitions, the general parenting factor nurturance was found to be a significant and strong predictor: parents were more likely to be highly involved and supportive if they demonstrated high levels of nurturance. It was also the only general parenting factor that was a significant predictor in the full model and had a very large effect size in the univariate model. Nurturance mainly represents the extent to which parents are responsive to their children's needs, are involved with and spend time with their child, and is also referred to as 'responsiveness' or 'involvement" (11,27). As such, nurturance may transfer from general parenting to involvement and supportiveness in food parenting.

The finding that parents of older children were less likely to covertly control and reward than those of younger children is consistent with earlier studies reporting on negative associations between child's age and instrumental and emotional feeding ${ }^{(43,44)}$, but different from a study finding no link between age and covert snack control $^{(45)}$. We found older parents to be more likely employing the 'low involvement and indulgent' pattern, which is reasonable given that parental involvement and monitoring tend to decline from childhood to adolescence $^{(46)}$. Lower-SEP parents were more likely to be highly involved and supportive, rather than being in the 'low involvement and indulgent' cluster, which is promising. Regarding the remaining predisposing factors, personality was of minor importance in predicting FPP, but part of the practices used by own parents did have a link with the food parenting patterns. More research is necessary to establish the significance of how parents were parented themselves in determining current parenting practices around energy balance-related behaviours.

\section{Implications for research and practice}

Based on the current study, planners of health promotion programmes aiming to reduce children's snack intake should focus on parental cognitions towards food parenting. Most importantly, self-efficacy and outcome expectations should be targeted. Although parental cognitions tend to be proximal to food parenting, interventions might be targeted 
at more fundamental and distal factors such as nurturance as well. Although we cannot draw conclusions on the mediation of general parenting via cognitions to parenting practices, Jago and colleagues recently found evidence for such a pathway ${ }^{(35)}$. Consequently, more sustainable change in parenting practices might be expected if change is achieved in general parenting ${ }^{(47)}$. Non-modifiable predictors including the child's age, parent's age and practices used by parents' own parents should be taken into account when developing interventions.

\section{Strengths and limitations}

A strength of the current study included the use of a broad set of potentially important factors. To the best of our knowledge, the present study is the first using a combination of contextual and intrapersonal factors in the prediction of food-related parenting practices. Parents were asked to reflect on their own parents' behaviours as well, which is an understudied perspective in the literature. It should be noted, however, that the self-report measures might have biased the results. There was one predictor that showed a different relationship in the univariate (i.e. OR $<1$ ) compared with the backward procedure (i.e. OR $>1$ ). Possibly, the low internal consistency of the scale concerned (i.e. 'selfefficacy towards permissiveness and pressure') caused this inconsistent result. The low internal consistency of five other scales, with Cronbach's $\alpha$ ranging from 0.50 to 0.59 , needs to be considered as well. Finally, the study was cross-sectional, implying that no causal inferences could be drawn. More specifically, parental cognitions such as self-efficacy or outcome expectations might have been constructed ad hoc because none existed or were aligned with (current) behaviour by parents, resulting in overestimated associations between cognitions and parenting practices ${ }^{(48)}$. In addition, we cannot draw conclusions on the causal direction between general parenting and FPP.

\section{Conclusion}

The present study showed that parental cognitions are important factors in explaining the use of FPP around snacking. It also found that the general parenting factor nurturance is a strong predictor variable to particularly distinguish highly involved parents from parents employing a pattern of low involvement. These results suggest that intervention developers should take measures aimed at increasing self-efficacy and educating parents about what constitute effective and ineffective parenting practices. Potentially, focusing on general parenting factors such as nurturance is necessary.

\section{Acknowledgements}

Acknowledgements: The authors would like to thank all parents who participated in this study and are grateful to
Ester Sleddens for her contribution to this study. Financial support: This research received no specific grant from any funding agency in the public, commercial or not-for-profit sectors. Conflict of interest: None. Authorship: D.W.M.G., S.P.J.K., N.K.d.V. and P.v.A. jointly designed the study. D.W.M.G. conducted the statistical analyses, made the initial interpretation of the results and wrote the draft version of the manuscript. S.P.J.K., N.K.d.V. and P.v.A. contributed to the interpretation of the results and revising the manuscript. All authors read and approved the final manuscript. Ethics of human subject participation: The study was exempt from ethical review.

\section{References}

1. Bell AC, Kremer PJ, Magarey AM et al. (2005) Contribution of 'noncore' foods and beverages to the energy intake and weight status of Australian children. Eur J Clin Nutr 59, 639-645.

2. Gevers DWM, Kremers SPJ, de Vries NK et al. (2016) Intake of energy-dense snack foods and drinks among Dutch children aged 7-12 years: how many, how much, when, where and which? Public Health Nutr 19, 83-92.

3. Piernas C \& Popkin BM (2010) Trends in snacking among US children. Health Aff (Millwood) 29, 398-404.

4. World Health Organization (2003) Diet, Nutrition and the Prevention of Chronic Diseases. Joint WHO/FAO Expert Consultation. WHO Technical Report Series no. 916. Geneva: WHO.

5. Adair LS \& Popkin BM (2005) Are child eating patterns being transformed globally? Obes Res 13, 1281-1299.

6. Duffey KJ, Rivera JA \& Popkin BM (2014) Snacking is prevalent in Mexico. J Nutr 144, 1843-1849.

7. Larson N \& Story M (2013) A review of snacking patterns among children and adolescents: what are the implications of snacking for weight status? Child Obes 9, 104-115.

8. Wang Z, Zhai F, Zhang B et al. (2012) Trends in Chinese snacking behaviours and patterns and the socialdemographic role between 1991 and 2009. Asia Pac J Clin Nutr 21, 253-262.

9. Craigie AM, Lake AA, Kelly SA et al. (2011) Tracking of obesity-related behaviours from childhood to adulthood: a systematic review. Maturitas 70, 266-284.

10. Singh AS, Mulder C, Twisk JWR et al. (2008) Tracking of childhood overweight into adulthood: a systematic review of the literature. Obes Rev 9, 474-488.

11. Gerards SMPL \& Kremers SPJ (2015) The role of food parenting skills and the home food environment in children's weight gain and obesity. Curr Obes Rep 4, 30-36.

12. Gevers DWM, Kremers SPJ, de Vries NK et al. (2014) Clarifying concepts of food parenting practices. A Delphi study with an application to snacking behaviour. Appetite 79, 51-57.

13. Gevers DWM, Kremers SPJ, de Vries NK et al. (2015) Patterns of food parenting practices and children's intake of energydense snack foods. Nutrients 7, 4093-4106.

14. Bartholomew Eldredge LK, Markham CM, Ruiter RAC et al. (2016) Planning Health Promotion Programs: An Intervention Mapping Approach. San Francisco, CA: Jossey-Bass.

15. Collins C, Duncanson K \& Burrows T (2014) A systematic review investigating associations between parenting style and child feeding behaviours. J Hum Nutr Diet 27, 557-568.

16. Ajzen I (2005) Attitudes, Personality, and Behaviour. Maidenhead: McGraw-Hill Education.

17. Flay BR \& Petraitis J (1994) The theory of triadic influence: a new theory of health behaviour with implications for preventive interventions. Adv Med Sociol 4, 19-44. 
18. Belsky J (1984) The determinants of parenting: a process model. Child Dev 55, 83-96.

19. Mena NZ, Gorman K, Dickin K et al. (2015) Contextual and cultural influences on parental feeding practices and involvement in child care centers among Hispanic parents. Child Obes 11, 347-354.

20. Bandura A (1998) Social Foundations of Thought and Action: A Social Cognitive Theory. Englewood Cliffs, NJ: Prentice-Hall.

21. Morawska A \& West F (2013) Do parents of obese children use ineffective parenting strategies? J Child Health Care 17, 375-386.

22. Fishbein M \& Ajzen I (1975) Belief, Attitude, Intention, and Behaviour: An Introduction to Theory and Research. Reading, MA: Addison-Wesley.

23. Central Committee on Research Involving Human Subjects (n.d.) Questionnaire research. http://www.ccmo.nl/en/ questionnaire-research (accessed September 2016).

24. Sociaal en Cultureel Planbureau (2017) Statusscores. http://www.scp.nl/Onderzoek/Lopend_onderzoek/A_Z_alle_ lopende_onderzoeken/Statusscores (accessed June 2017).

25. Fredriks AM, van Buuren S, Wit JM et al. (2000) Body index measurements in 1996-7 compared with 1980. Arch Dis Child 82, 107-112.

26. Gerris JRM, Houtmans MJM, Kwaaitaal-Roosen EMG et al. (1998) Parents, Adolescents and Young Adults in Dutch Families: A Longitudinal Study. Nijmegen: Institute of Family Studies.

27. Sleddens EFC, O'Connor TM, Watson KB et al. (2014) Development of the Comprehensive General Parenting Questionnaire for caregivers of 5-13 year olds. Int J Behav Nutr Phys Act 11, 15.

28. Field A (2013) Discovering Statistics Using IBM SPSS Statistics. London: SAGE Publications Ltd.

29. Myers RH (1990) Classical and Modern Regression with Applications. Belmont, CA: Duxbury Press.

30. Barlow SE (2007) Expert committee recommendations regarding the prevention, assessment, and treatment of child and adolescent overweight and obesity: summary report. Pediatrics 120, Suppl. 4, S164-S192.

31. Bohman B, Nyberg G, Sundblom E et al. (2014) Validity and reliability of a parental self-efficacy instrument in the healthy school start prevention trial of childhood obesity. Health Educ Behav 41, 392-396.

32. Ek A, Sorjonen K, Nyman J et al. (2015) Child behaviours associated with childhood obesity and parents' self-efficacy to handle them: confirmatory factor analysis of the Lifestyle Behaviour Checklist. Int I Behav Nutr Phys Act 12, 36.

33. Gerards S, Hummel K, Dagnelie PC et al. (2013) Parental self-efficacy in childhood overweight: validation of the Lifestyle Behaviour Checklist in the Netherlands. Int J Behav Nutr Phys Act 10, 7.

34. Hnatiuk JA, Salmon J, Campbell KJ et al. (2015) Tracking of maternal self-efficacy for limiting young children's television viewing and associations with children's television viewing time: a longitudinal analysis over 15-months. BMC Public Health 15, 517.
35. Jago R, Wood L, Zahra J et al. (2015) Parental control, nurturance, self-efficacy, and screen viewing among 5-to 6-year-old children: a cross-sectional mediation analysis to inform potential behaviour change strategies. Child Obes 11, 139-147.

36. Nyberg G, Sundblom E, Norman Å et al. (2015) Effectiveness of a universal parental support programme to promote healthy dietary habits and physical activity and to prevent overweight and obesity in 6-year-old children: the Healthy School Start Study, a cluster-randomised controlled trial. PLoS One 10, e0116876.

37. Ruiter EL, Fransen GA, Molleman GR et al. (2015) The effectiveness of a web-based Dutch parenting program to prevent overweight in children 9-13 years of age: study protocol for a two-armed cluster randomized controlled trial. BMC Public Health 15, 148.

38. Lally P, Cooke L, McGowan L et al. (2012) Parents' misperceptions of social norms for pre-school children's snacking behaviour. Public Health Nutr 15, 1678-1682.

39. Andrews KR, Silk KS \& Eneli IU (2010) Parents as health promoters: a theory of planned behaviour perspective on the prevention of childhood obesity. J Health Commun $\mathbf{1 5}$, 95-107.

40. Baranowski T, Beltran A, Chen T-A et al. (2013) Psychometric assessment of scales for a Model of Goal Directed Vegetable Parenting Practices (MGDVPP). Int J Behav Nutr Phys Act 10, 110.

41. Baranowski T, Beltran A, Chen T-A et al. (2015) Predicting use of ineffective vegetable parenting practices with the Model of Goal Directed Behaviour. Public Health Nutr 18, 1028-1035.

42. Diep CS, Beltran A, Chen T-A et al. (2015) Predicting use of effective vegetable parenting practices with the Model of Goal Directed Behaviour. Public Health Nutr 18, 1389-1396.

43. Raaijmakers LG, Gevers DWM, Teuscher D et al. (2014) Emotional and instrumental feeding practices of Dutch mothers regarding foods eaten between main meals. $B M C$ Public Health 14, 171.

44. Hendy HM \& Williams KE (2012) Mother's feeding practices for children 3-10 years of age and their associations with child demographics. Appetite 58, 710-716.

45. Brown KA, Ogden J, Vögele C et al. (2008) The role of parental control practices in explaining children's diet and BMI. Appetite 50, 252-259.

46. Melbye EL, Ogaard T, Overby NC et al. (2013) Parental food-related behaviours and family meal frequencies: associations in Norwegian dyads of parents and preadolescent children. BMC Public Health 13, 820.

47. Kitzmann KM \& Beech BM (2011) Family-based interventions for pediatric obesity: methodological and conceptual challenges from family psychology. J Fam Psychol 20, 175-189.

48. Armitage CJ \& Conner M (1999) The theory of planned behaviour: assessment of predictive validity and 'perceived control'. Br J Soc Psychol 38, 35-54. 